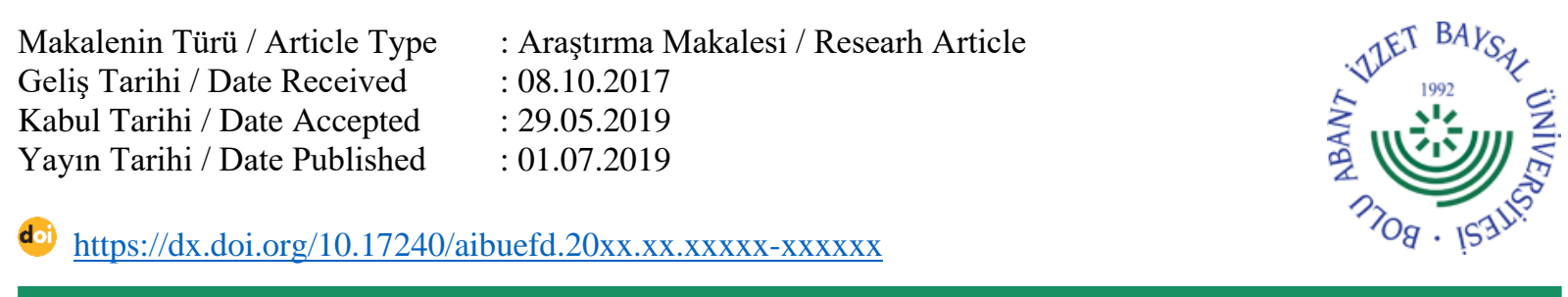

\title{
MUTLULUĞUN EMPATİ, AFFETME VE YAŞAM DOYUMU ARASINDAKİ ARACI ROLÜ: BİR YOL ANALIZİ
}

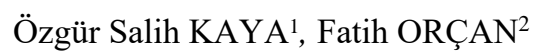

ÖZ

$\mathrm{Bu}$ araştırmanın amacı, üniversite öğrencilerinin empatik eğilimleriyle yaşam doyumu ve affetme düzeyleri arasındaki ilişkide mutluluğun aracılık rolünün olup olmadığını saptamaktır. Araştırma ilişkisel tarama modeline uygun olarak düzenlenmiştir. Araştırmanın verileri 2016-2017 eğitim öğretim yılı güz yarıyılında bir devlet üniversitesinde öğrenim gören 209 kız, 142 erkek olmak üzere toplam 351 öğrenciden oluşmaktadır. Öğrencilerin yaş ortalaması 20.3'tür. Araştırmada Kişisel Bilgi Formu, Toronto Empati Ölçeği, Yaşam Doyumu Ölçeği Türkçe Formu, Öznel Mutluluk Ölçeği ve Affedicilik Ölçeği kullanılmıştır. Hipotez edilen yol modelini incelemek için veriler SPSS 24 ve Mplus 5.1 programları kullanılarak analiz edilmiştir. Verilerin normal dağıldığı gözlenmiştir ve bu yüzden maksimum olabilirlik tahmin metodu kullanılmıştır. Çoklu bağlantı probleminin olmadığ 1 ve model veri uyum değerlerinin kabul edilebilir olduğu görülmüştür $\left(\chi^{2}=1.58, \mathrm{CFI}=.99\right.$, TLI=.97, RMSEA=.04, $\mathrm{SRMR}=.01)$. Sonuçta, empatinin affetme ve yaşam doyumu üzerinde doğrudan bir etkisinin olduğu bulunmuştur. Ayrıca mutluluğun empati, yaşam doyumu ve affetme arasında aracı rolü olduğu saptanmıştır.

Anahtar Kelimeler: Empati, mutluluk, yaşam doyumu, affetme, yol analizi

\section{MEDIATING ROLE OF HAPPINESS BETWEEN EMPATHY, FORGIVENESS, LIFE SATISFACTION: A PATH ANALYSIS}

\section{ABSTRACT}

The purpose of this study was to determine whether happiness is a mediator variable in the relationship among empathy, life satisfaction and forgiveness for college students. The study was designed according to the relational screening model. Data were collected from 209 female and 142 male, a total of 351 students studying at Recep Tayyip Erdoğan University in 20162017 academic year. Average age of the students was 20.3. Personal information form, Toronto Empathy Scale, Life Satisfaction Scale Turkish Form, Subjective Happiness Scale and Forgiveness Scale were used in this study. Data were analyzed using SPSS 24 and Mplus 5.1 programs to explore hypothesized path model. The data were normally distributed and therefore Maximum Likelihood estimation method was used. It was seen that there was no multicolinearity problem and that the modeldata fit index values were acceptable $\left(\chi^{2}=1.58, \mathrm{CFI}=.99\right.$, TLI=.97, RMSEA=.04, SRMR=.01). Consequently, empathy has been found to have a direct effect on forgiveness and life satisfaction. In addition, it has been found happiness acted as a mediator in the relationship among empathy, life satisfaction and forgiveness.

Keywords: Empathy, happiness, life satisfaction, forgiveness, path analysis

\footnotetext{
${ }^{1}$ Recep Tayyip Erdoğan Üniversitesi, Eğitim Fakültesi, ozgursalih.kaya@erdogan.edu.tr, (1) https://orcid.org/0000-0001-8535-290X

${ }^{2}$ Trabzon Üniversitesi, Eğitim Fakültesi, fatihorcan.trabzon@hotmail.com, 는ttps://orcid.org/0000-0003-1727-0456
} 


\section{GíRiş}

Sosyal bir varlık olan insanın karşısındaki kişinin ne düşündüğünü, ne hissettiğini ve ne tepki verebileceğini anlamaya başlamasının nereye dayandığı bilinmemektedir. Günlük hayatta kişilerarası ilişkilerde "Seni anlıyorum.", "Ne hissettiğini hissedebiliyorum.", "Şu an ne diyeceğini biliyorum." gibi cümleler siklıkla kullanılmaktadır. Bireyin karşısındaki kişinin davranışlarını ve neler hissettiğini tam olarak anlaması mümkün olmamaktadır. Çünkü bireylerin birbiriyle olan ilişkisi karşısındakini anlama isteği ve derecesini etkilemektedir. Hoffman (1978) insanların kendilerine benzer insanlarla empati kurmada daha istekli ve başarılı olduğunu söylemiştir. Winnet (2001) empatiyi, kendini başkasının yerine koyarak, onun duygularını anlama becerisi olarak tanımlamıştır. İnsanın karşısındaki kişinin duygularını doğru anlayıp, bunları karşısındaki kişiye aktarabildiğinde empati kurmayı başarmış sayılmaktadır (Derman, 2011). Kendileri ile empati kurulduğunu fark eden insanlar daha çok anlaşıldığını ve önemsendiğini hissederler. Başkaları tarafından anlaşılmak ve önemsendiğini hissetmek bireyi rahatlatıp kendisini daha iyi hissetmesini sağlayacaktır (Yüksel, 2004). Bu durum kişilerarası iyi ilişkiler geliştirebileceği gibi var olan ilişkiyi güçlendirmeye ve empati kuran kişinin karşısındaki kişinin duygu ve düşüncelerini anlama becerisi kazanmasına yardımcı olabilir. Kişiler arası ilişkileri başlatmada, sürdürmede ve geliştirmede kuşkusuz çok önemli bir yere sahip olan empati son yıllarda psikoloji alanında önemli bir araştırma konusu olmuştur. Yapılan araştırmalarda empati ile problem çözme becerisi (Köroğlu, 2012; Yılmaz, 2011), benlik saygısı (Karataş, 2012; Sal1, 2013) ile pozitif yönde ilişkili iken narsisizm (Demiralp, 2017; Kiraz, 2011) ile negatif yönde ilişkilidir.

Pozitif psikoloji hareketinden türeyen öznel mutluluk sağlıklı oluşun, neşenin ve huzurun psikolojik durumu olarak tanımlanır (Lyubomirsky, 2001). Seligman (2002), mutluluğun olumlu duygu, yaşama bağlı olma ve yaşamın anlamı olmak üzere üç boyuttan oluştuğunu ileri sürmektedir. Olumlu duygu, geçmiş, şu an ve geleceğe ilişkin olumlu duygulara sahip olmayı ve bu duyguların yoğunluğunu artırmak için gerekli becerileri öğrenmeyi; yaşama bağlı olma, bireyin iş yaşamında, sosyal ilişkilerinde ya da serbest zamanlarında zevk aldığı etkinlikleri yapması ve bu etkinliklerden keyif almasını; anlamlı bir yaş̧am sürme ise, bireyin yeteneklerini ve güçlü yanlarını topluma hizmet etmede kullanabilmesini ifade eder. Bireyin bu doğrultuda yaptığı etkinlikler yaşamdan daha çok doyum almasını (Peterson, Park ve Seligman, 2005) ve sonuçta kendini daha mutlu hissetmesini sağlayacaktır (Lyubomirsky, King ve Diener, 2005). Diener, Suh, Lucas ve Smith (1999) mutlu kişiyi genç, sağlıklı, iyi eğitimli, iyi gelir sahibi, başkalarıyla olan iletişim becerileri yüksek, kaygı düzeyi düşük, inançlı, evli, iş ahlakı ve tevazu sahibi kişi olarak tanımlar. Çankaya'ya (2008) göre mutlu olmayı etkileyen faktörler arasında kişilik, başkalarıyla kurulan ilişkiler, kültür, eğitim, gelir, din, psikolojik ihtiyaçlar (özerklik, yeterlik, ilişkili olma ihtiyacı) bulunmaktadır. Bireylerin yaşam değerlendirmeleri ne kadar çok olumlu duygu ve düşüncelerle doluysa mutlu olma düzeyleri o kadar yüksek olmaktadır. Buradan hareketle yaşamlarından doyum alan, sıklıkla olumlu duygular hisseden bireylerin mutlu oldukları söylenebilir. Literatürde mutlu bireylerin çatışma çözme becerisi (Bélanger, Laporte, Saborrin ve Wright, 2015; Kaya ve Demir, 2017) ve benlik saygılarının (Kangal, 2013; Lyubomirsky, Tkach ve DiMatteo, 2006) daha yüksek olduğu görülürken, narsistik davranış eğilimlerinin daha az olduğuna (Erkutlu, 2014; Twenge ve Campbel, 2010) dikkat çekilmiştir.

İlk olarak Neugarten tarafından kullanılan yaşam doyumu, öznel iyi oluşun bilişsel bir bileşeni ve kişinin yaşamıyla ilgili bilişsel yargıları içermektedir (Diener, 1984). Alanyazında yaşam doyumu, mutluluk ve öznel iyi oluş kavramları ile birlikte ele alınır ve çoğu zaman birbirinin yerine kullanılır. Bu kavramlar eş anlamlı olarak kullanılsa da aslında farklı anlamlar içerirler. Aralarındaki bu farkın açıklanmasının hem kuramsal çerçeveyi belirlemede fayda sağlayacağı hem de kavramsal farkın somutlaştıılmasını kolaylaştıracağı düşünülmektedir. Andrews ve Withey (1976) yaşam doyumunun öznel iyi oluşun bilişsel boyutunu oluşturduğuna değinmiştir. Öznel iyi oluş bireyin belirli psikosomatik belirtilere ilişkin duyguları ön plana çıkarırken, yaşam doyumu yaşam hakkında ayrıntılı bir değerlendirme yapmaktadır (Veenhoven, 1996). Eryılmaz ve Öğülmüş (2010) mutluluğun psikolojik anlamının öznel iyi oluş olduğunu ifade etmişlerdir. Yaşam doyumunun öznel iyi oluşun bilişsel boyutu olduğu düşünüldüğünde, aslında yaşam doyumunun mutluluğun bir alt boyutu olduğu düşünülebilir. Mutluluk, bireyin kendisine en yüksek hedef olarak belirlediği değerler iken (Akarsu, 1997), yaşam doyumu, kişilerin çalışma hayatı haricinde sahip oldukları yaşama karşı aldıkları tavırdır (Özdevecioğlu, 2003). Keser'e (2003) göre mutluluk durumu daha ileriye dönük iken yaşam doyumu ise şimdiki zamanda yaşanılan bir durumdur. Kısacası mutluluk bireyin ulaşmak istediği bir hedef iken yaşam doyumu kişinin sahip oldukları ile ne kadar doyum sağladığıdır.

Yaşam doyumu kişinin yaşama dair olan beklenti ve amaçlarının gerçekte ne derece karşılandığı sonucudur. Yaşam doyumu denildiğinde, belli bir duruma özgü doyum değil, bütün bir yaşantıya iliş̧in alınan doyum akla gelir (Çevik, 2010). Yaşam doyumu, üniversite çağındaki gençler için önemli bir konudur. Üniversiteye başlayan gençlerin büyük bir kısmı eğitim için yaşadıkları şehirden başka bir şehre gitmektedir. Bu değişiklik bir yandan üniversite hayatına adapte olmalarını gerektirirken diğer yandan yaşamlarında farklılıklara ve psikososyal problemlere sebep olmaktadır (Demirel ve diğ., 2006). Literatür incelendiğinde yaşam doyumunun problem çözme becerileri (Bozoğlan, 2014; Kaya, 2018) ve benlik saygısı (Demirel ve Canat, 2004; Yıldız ve Baytemir, 2016) ile 
pozitif yönde; narsisizm (Anderson ve Costello, 2009; Hofmann, Luhmann, Fisher, Vohs ve Baumeister, 2014) ile negatif yönde ilişkili olduğu bulunmuştur.

Affetme, son yıllarda araştırmalarda öne çıkan bir kavramdır. Affetme kavramı üzerine önde gelen araştırmacılardan biri olan Enright'a (1996) göre affetme, bireyin olumsuz kararlarına ve kişiyi haksız bir şekilde incitmiş kişilere karşı olan haktan isteyerek vazgeçmesi ve bunu yaparken aynı zamanda o kişiye karşı şefkat, cömertlik ve hatta sevgi gibi olumlu duyguları beslemesidir. Thompson ve diğerleri (2005) affetmenin tek boyutlu bir yapı olmadığını ileri sürerek, bireyin hem kendini hem de başkasını affetmesine vurgu yapmıştır. Kendini affetme, yapılan bir hatadan sonra kişinin kendini sevip saygı duyabilmesidir. Kendini affetme iki durumda gerçekleşmektedir. Birincisi kişinin başka birine verdiği zarar nedeniyle, ikincisi ise kişinin kendisine verdiği zarar nedeniyle kendini affetmesidir (Hall ve Fincham, 2005). Fincham, Hall ve Beach (2006), kendini affetme ile başkasını affetme arasında fark olduğunu vurgulamaktadırlar.

Başkalarını affetme, bireyin onu haksız yere inciten kişiye karşı kızma ve olumsuz değerlendirmeden isteyerek vazgeçmesi ve o kişiye karşı merhamet, cömertlik ve sevgi gibi duyguların teşvik edilmesidir (Enright, 1996). Exline, Worthington, Hill ve McCullough (2003), başkalarını affetme bireyin kendisini inciten kişiye yönelik olumsuz duygularını azaltıp olumlu davranışlarda bulunmasıyla gerçekleşen içsel bir süreçtir. Yapılan araştırmalarda empatinin (Worthington, 2006), affetmeyi kolaylaştıııc etkisinin olduğu söylenmektedir. Affetme ile ilgili alan yazına bakıldığında problem çözme becerileri (Fincham, Beach ve Davila, 2004; Ysseldyk ve Matheson, 2008; ve benlik saygısı (Asıc1, 2013; Dillon, 2001) ile pozitif yönde; narsisizm (Eaton, Struthers ve Santelli, 2006; Strelan, 2007) ile negatif yönde ilişkili olduğu bilinmektedir.

Hümanistik yaklaşıma göre empati, içsel durumun ve içsel özelliklerin, hislerin, iç dünyaya ilişkin deneyimlerin anlamlandırılmasıdır. Hümanistik görüş, empatide diğer bireyin duygularına odaklanmakta ve empati kuran bireyin içsel dünyayı tanımlamaya yönelik yeteneğinin olması gerektiğine dikkat çekmektedir (Hac1, 2011). Daha önce belirtildiği gibi mutluluk ve yaşam doyumu birbiriyle iç içe ve yakın anlamlı kavramlardır. Diener, Emmons, Larsen ve Griffin'a (1985) göre yaşam doyumu, mutlu olmanın önemli bir öğesidir. Empati gibi kişilerarası ilişkilerde ve kişinin kendisi isteği dışında gerçekleşen olayların sonucunda bireyin yaşam doyumu ve mutluluk düzeyi değişmektedir (Özdemir ve Koruklu, 2011; Russel, 2003). Bireyin diğerleri ile olan ilişkisinde veya bir olay karşısındaki yaşam doyumu ve mutluluk düzeyinin etkilenmesinde bireyin içsel bir değerlendirmesi söz konusudur. Tarhan'a (2005) göre her ne kadar diğer kişiler ve bireyin kendisi dışındaki olaylar bireyin yaşam doyumunu ve mutluluğunu etkilese de bireyin kişilerarası ilişkilere ve olaylara bakış açısı atfettiği değer ve içsel değerlendirmesi önemlidir. Yani mutluluk ve yaşam doyumu bireyin hem çevresel koşullarına hem de kendisine bağlıdır. Diener, Suh, Lucas ve Smith (1999) bireyin işi, ailesi, yakın çevresi gibi dışsal faktörlerin bireyin yaşam doyumunu ve mutlu olma biçimini etkilediği gibi, benlik algısı, kişisel farkındalığının da bireyin yaşamdan aldığı doyum ve mutluluğuna etkisi olduğunu savunmuştur. Daha önce bahsedildiği gibi affetme tek boyutlu bir yap1 olmayıp bireyin kendisine yönelik veya başkalarıyla olan ilişkisi sonucu ortaya çıkan bir yapıdır. Worthington'un (1998) ortaya koyduğu affetme piramit modelinde insanların başkaları ile olan ilişkisinde karşısındakinin hatalarını affedebilmesinin onların mutluluk düzeyleri ve iyilik halleri ile ilişkili olabileceğini ifade etmiştir. Nitekim literatürde bunu destekleyen çalışmalar mevcuttur. Maltby, Day and Barber (2005) affetme ve mutluluk arasında pozitif yönde anlamlı bir ilişki olduğunu bulmuşlardır. Chan (2013) yapmış olduğu bir araştırmada affetme ve mutluluğun pozitif yönde ilişkisinin olduğunu belirtmiştir. Enright ve diğerlerinin (1996) oluşturduğu affetme süreç modelinde, affetmenin diğer bireylerle ilişkili olduğunu savunmaktadır. Bu modelde dört evre bulunmaktadır. Ortaya çıkma evresinde birey önce yapılan davranışın çok da kötü bir şey olmadığını anlar. Karar verme evresinde, affetmenin ne olduğunu sorgulayarak farkındalığını arttırır. Çalışma evresinde kendisini karşındakinin yerine koyar. Hatayı kendisi yaptıysa neden yaptı̆̆ını, karşısındaki yaptıysa sebebini anlamaya çalışır. Bunun için kendisine ve diğerlerine dair içsel bir değerlendirme yapar. Son evre olan derinleştirme evresinde ise, işlenen suçu ve olayı anlamlandırarak kendisini veya karşısındakini affeder. Affetmenin süreç modelinde bireyin yaşadığı olay sonucunda içsel bir değerlendirme söz konusudur. Bireyin affedip affetmemesi ise kendisini karşısındakinin yerine koyması yani onunla empati kurmasından geçer. Walker ve Gorsuch' a (2004) göre affetme modellerinin ortak noktalarından birisi de empati yapabilme becerisidir. Enright ve diğerlerine (1996) göre başkalarını affetmek için bireyin empati yapabilme becerisine sahip olması gerektiğini vurgulamışlardır. Bir başka çalışmada Alpay (2009) yapmış olduğu çalışmada affetme ve empatinin ilişkili olduğunu belirtmiştir. Dolayısıyla bireyin kendisini başkasının yerine koyup sergilenen davranışın kaynağını anlaması itibariyle affetme ve empatinin ilişkili kavramlar olduğu anlaşılmaktadır.

Literatür incelemesi yapıldığında empati, mutluluk, yaşam doyumu ve affetme kavramlarının ortak değişsenlerle (problem çözme becerisi, benlik saygısı, narsisizm v.b.) çalışıldığı görülmüştür. Bu araştırmadaki değişkenlerin aynı psikolojik kavramla çalışılması araştırmanın kuramsal temelinin oluşturulmasına ışık tutmuştur. Kuramsal çerçeve oluşturulduktan ve yukarıda sunulduktan sonra yapılan literatür incelemesinde değişkenler arasındaki iliş̧kinin incelendiği çalışmalara göz atıldığında Baştuğ (2009) empati ve yaşam doyumu arasında arasında pozitif yönde istatistiksel olarak anlamlı bir ilişki bulmuştur. Barrington-Leigh ve Helliwell (2008) yapmış oldukları 
araştırmada empatinin yaşam doyumu üzerinde etkili olduğundan bahsetmişlerdir. Lee Brenna ve Daly (2001) yaptıkları çalışmada empatinin yaşam doyumunun anlamlı bir yordayıcısı olduğunu bulmuşlardır. Empatik becerileri yüksek olan bireylerin yaşam doyumlarının da yükseldiği belirlenmiştir. Başkalarını anlayan ve iyi ilişkiler geliştiren bireylerin yaşamdan aldıkları doyumun daha yüzsek olduğu düşünülmektedir. Mutluluğun yaşam doyumu ile çok benzer bir yapı olmasına karsın aralarında farkların neler olduğu yukarıda belirtilmiştir. İncelenen literatürde mutluluğun yaşam doyumu ile pozitif yönde ilişkili olduğu anlaşılmaktadır (Cohn, Fredrickson, Brown, Mikels ve Conway, 2009; Peterson, Park ve Seligman, 2005). Peterson, Ruch, Beermann, Park ve Seligman (2007) yaptıkları çalışmada yaşam doyumunun anlamlı yordayıcılarını incelemişlerdir. Yaşam doyumunun en güçlü yordayıcısı mutluluk, yaşamın anlamı ve yaşama bağlılık olduğu bulunmuştur. Mutluluğun, yaşam doyumunun güçlü bir yordayıcısı olması ortak yapılar olduğunu göstermekte ve bireylerin kendilerini mutlu hissettiklerinde hayattan aldıkları zevk, haz ve duygusal iyi oluşun daha fazla olduğu düşünülmektedir. Empati ile mutluluk arasındaki ilişkiyi inceleyen çalışmalara bakıldığında ise, Thomas ve diğerlerinin (2007) yapmış olduğu çalışmada empati ve mutluluğun birbiri ile ilişki olduğu, empati yapabilme becerisi yüksek olan bireylerin kedilerini daha mutlu hissettiklerini ve kişilerarası ilişsilerinin daha iyi olduğunu bulmuşlardır. Shanafelt ve diğerlerinin (2005) yapmış oldukları çalışmada empati arttıkça bireylerin mutluluk düzeylerinin de arttığı sonucuna ulaşmışlardır. Araştırmanın amacı doğrultusunda mutluluk ilişkili olduğu düşünülen bir diğer kavram affetmedir. Maltby, Macaskill ve Day (2001)'a göre mutlu bireyler daha affedici davranışlar sergilediği gibi affeden bireylerin de daha mutlu oldukları ve genel sağlık açısından kendilerini daha iyi hissettiklerini belirtmişlerdir. Çardak (2012) yapmış olduğu çalışmada üniversite öğrencilerinin mutluluk ve affetme düzeyleri arasında pozitif yönde anlamlı bir ilişki bulmuştur. Bir başka çalı̧̧ma ise Koç, İskender, Çolak ve Düşünceli (2016) tarafından yapılmıştır. Bu çalışmada affetmenin mutluluk ile pozitif yönde anlamlı ilişkisinin olduğu bulunmuştur. Affetmenin empati ile olan ilişkisine bakıldığında, Toussaint ve Webb (2005) yaptıkları çalışmada empati ve affetme arasında anlamlı bir ilişki bulmuşlardır. Rangganadhan ve Todorov (2010) yaptıkları çalışmada empatinin affetmenin güçlü bir yordayıcısı olduğunu belirtmişlerdir.

Yukarıda sunulan literatürde mutluluğun empati tarafından açıklanırken, yaşam doyumu ve affetmeyi açıkladığı görülmektedir.

\subsection{Araştırmanın Amacı}

Yukarıda belirtilen teorik alt yapıdan yola çıkarak bu araştırmanın amacı empatinin yaşam doyumu ve affetme arasındaki ilişkide mutluluğun aracı rolünün incelenmesi olarak belirlenmiştir. Yukarıda sunulan bilgiler ışığında ülkemizdeki öğrencilerin empati, mutluluk, yaşam doyumu ve affetme arasındaki ilişkiler ağını ortaya çıkartmak için "Üniversite öğrencilerin yaşam doyumu ve affetmenin empati ilişkisinde mutluluk aracılık yapmakta mıdır?" sorusuna yanıt aranmıştır. Yukarıdaki kuramsal açıklamalar ve ilgili araştırmalar ışığında hipotez edilen bir model (Hipotez modeli) oluşturulmuş ve bu model aşağıda sunulmuştur. Model iki hipotezden oluşmakta ve modelde bu hipotezlerdeki değişkenler arasındaki ilişkilere yer verilmiştir. Araştırmanın hipotez modeli Şekil 1'de verilmiştir. Çoklu regresyon analizi yardımıyla bu model bir bütün olarak değerlendirilecektir. Bu çerçevede aşağıdaki sorulara da cevap aranacaktır:

1- Mutluluk, empati ve yaşam doyumu arasında aracı bir role sahip midir?

2- Mutluluk, empati ve affetme arasında aracı bir role sahip midir?

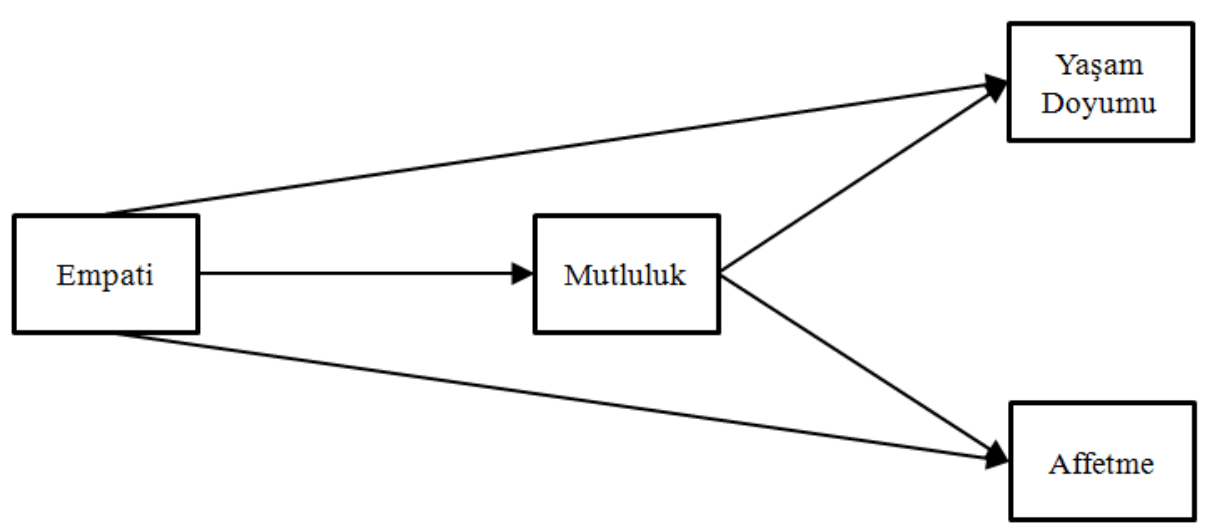

Şekil 1. Hipotez Modeli

Şekil 1'de araştırmanın hipotez modeli sunulmuştur. Bu modelde affetme ve yaşam doyumunu doğrudan ve dolalı olarak etkileyen değişkenler gösterilmiştir. 


\subsection{Araştırmanın Önemi}

Ülkemizde pozitif psikolojinin yaygınlaşmasıyla birlikte yukarıda açıklanan kavramlara olan ilgi artmıştır. Affetme ve yaşam doyumu kavramlarının empati ile olan ilişkisini inceleyen çalışmalar hem yurt içi hem yurt dışı literatürde yok denecek kadar azdır. Söz konusu değişkenlerin birbiri ile iç içe olması ve insan yaşamının her anında kendini göstermesi itibariyle bu ilişkiye vurgu yapılmasının önemli olduğu düşünülmektedir.

\section{YÖNTEM}

$\mathrm{Bu}$ araştırmada, öğretmen adaylarının empatik eğilimlerinin yaşam doyumu ve affetme düzeyleri arasındaki ilişkide mutluluk değişkeninin aracı rolünü açıklamak istenmiştir. Bu hususta yapısal eşitlik modellerinden yol analizi tercih edilmiştir.

\section{1. Çalışma Grubu}

Araştırmanın örneklemini 2016-2017 eğitim öğretim güz yarıyılında Türkiye'de bir devlet üniversitesinin Eğitim Fakültesi'nde öğrenim gören ve seçkisiz örnekleme yöntemi ile seçilmiş 351 kişi oluşturmaktadır. Katılımcıların 209'u kadın (\%59.5), 142'si erkek (\%40.5) öğrencidir. Örneklem grubunun yaşları 18-24 arasında değişmekte olup yaş ortalaması 20.3 olarak hesaplanmıştır.

\subsection{Veri Toplama Araçları}

\subsubsection{Toronto Empati Ölçeği}

Toronto Empati Ölçeği Spreng, Kinnon, Mar ve Levine (2009) tarafından geliştirilmiş 13 maddelik, 5'li likert tiptedir. Ölçek Totan, Doğan ve Sapmaz (2012) tarafından Türkçe'ye uyarlanmıştır. Yapı geçerliği için doğrulayıcı faktör analizi yapılmış ve uyum indeksi değerlerine bakılmıştır. Uygulanan DFA sonucu uyum indeksi değerlerinin makul düzeyde olduğu ve orijinal formun faktör yapısının Türk örneklemde doğrulandığ1 görülmüştür $[\chi 2=$ 234.67, $\mathrm{df}=64, \chi 2 / \mathrm{df}=3.67, \mathrm{NFI}=.91, \mathrm{GFI}=.94, \mathrm{RFI}=.90, \mathrm{IFI}=.94, \mathrm{CFI}=.94, \mathrm{RMSEA}=.07, \mathrm{RMR}=.05]$. Ölçeğin güvenirliği test tekrar test ve iç tutarlık yöntemleriyle incelenmiştir. Buna göre TEÖ'nin iç tutarlık güvenirlik katsayısı .79 olarak bulunmuştur. İki hafta arayla gerçekleştirilen, test tekrar test yöntemiyle hesaplanan güvenirlik katsayısı ise .73 olarak bulunmuştur. Bu araştırmadaki verilerden elde edilen iç tutarlılık güvenirlik katsayısı Toronto empati ölçeği için .83 olarak hesaplanmıştır. Ölçek tek boyuttan oluşmakta ve ölçekten yüksek puan alınması empati düzeyinin yüksek olduğuna işaret etmektedir.

\subsubsection{Yaşam Doyumu Ölçeği}

Yaşam Doyumu Ölçeği, Diener ve arkadaşları (1985) tarafından geliştirilen 7'li likert ve 5 maddeden oluşan bir ölçektir. Diener ve arkadaşları (1985) YDÖ’ nün iç tutarlık güvenirlik katsayısını .87 ve test-tekrar test güvenirlik katsayısını ise .82 olarak bulmuşlardır. Ölçekten yüksek puan alınması yaşam doyumunun yüksek olduğunu göstermektedir. Ölçek Yetim (1991) tarafından Türkçeye uyarlanmıştır. Yetim (1991), Yaşam Doyumu Ölçeği'nin iç tutarlık güvenirlik katsayısını .76, test tekrar test güvenirlik katsayısını .85 bulmuştur. Bu araştırmada yaşam doyumu ölçeği için iç tutarlılık güvenirlik katsayısı .90’dır.

\subsection{3. Öznel Mutluluk Ölçeği}

Akın ve Satıcı (2011) tarafından geliştirilen Öznel Mutluluk Ölçeği, 4 maddeden ve 7'li likertten oluşmaktadır. Ölçekte 4 numaralı madde ters puanlanmaktadır. Yapı geçerliği için doğrulayıcı faktör analizi yapılmış ve analiz sonucunda uyum değerlerine bakılmıştır ve uyum indeksi değerlerinin kabul edilebilir düzeyde olduğu görüşmüştür (x2/df=.71, AGFI=.99, CFI=1.00, GFI=1.00, IFI=1.00, RFI=.98, RMSEA=.00, SRMR=.01 olarak bulunmuştur. Ölçek maddelerinin faktör yükleri .34 ile .84 arasında değişmektedir. ÖMÖ’nün güvenirlik analizlerinde iç tutarlılık güvenirlik katsayısı .86 olarak bulunmuştur. Ölçeğin madde-test korelasyonlarının ise .55 ile .76 arasında sıralandığı görülmüştür. Bu araştırmada öznel mutluluk ölçeği için iç tutarlılık güvenirlik katsayısı .90 bulunmuştur.

\subsubsection{Affedicilik Ölçeği}

Affedicilik Ölçeği Berry ve diğerleri (2004) tarafından geliştirilmiş 10 maddeden oluşan tek boyutlu bir ölçektir. Ölçek Sarıçam ve Akın (2013) tarafından Türkçeye uyarlanmıştır. AFA sonucu Kaiser Meyer Olkin testi katsayısı .67 , Barlett testi $\chi 2$ değeri $518.35(\mathrm{p}<.001, \mathrm{sd}=120)$ olduğu görülmüştür. Ölçeğin yap1 geçerliği için DFA yapılmış ve analiz sonucu model uyum indeksi değerleri kabul edilebilir düzeydedir. $\left(\chi^{2}=106.47\right.$, sd= 32 , AGFI= $.91, \mathrm{CFI}=.89, \mathrm{GFI}=.95, \mathrm{SRMR}=.06, \mathrm{RMSEA}=.08)$. Ölçeğin faktör yükleri .52 ile .77 arasında değişmekte, iç 
tutarlık katsayısı .67 olarak bulunmuştur. Test-tekrar test güvenirlik katsayısı .88 olarak bulunmuştur. Bu araştırmada affedicilik ölçeği için iç tutarlılık güvenirlik katsayısı .74 bulunmuştur.

\subsection{Verilerin Analizi}

354 kişiden alınan veriler ilk olarak SPSS 24.0 programına girilmiş, kayıp veriler ve uç değerlerin olup olmadığı tespit edilmiştir. Uç değer olduğu düşünülen, ölçek formlarından birer tanesini doldurmayan bir kişi ve rastgele işaretleme yaptığı düşünülen 2 kişi veri setinden çıkarılmıştır ve araştırmaya 351 kişi ile devam edilmiştir. Verilerin analizi SPSS 24 paket programında pearson momentler çarpımı korelasyonu ve Mplus 5.1 paket programı ile yapılmıştır.

\section{BULGULAR}

Schafer (1997) kayıp verilerin oranı \%10’un altında olduğu durumlarda kayıp veri olan satırların veri setinden çıkarılacağı gibi seri ortalaması değerlerinin atanabileceğini belirtmiştir. Her bir madde için kayıp veri oranına bakılmış ve en fazla kayıp veri olan madde için \%2 olduğu tespit edilmiştir. Bu oran \%10'un altında olduğundan dolayı makul olarak kabul edilmiş ve kayıp verilere seri ortalaması değerleri atanmıştır. Bu bölümde ilk olarak verilerin normal dağılım gösterip göstermediğini anlamak için basıklık ve çarpıklık değerleri hesaplanmıştır. Basıklık ve çarpıklık değerleri -2 ile +2 bu değerler $+1,-1$ arasında olması gerekmiyor mu? arasında olduğu görülmüştür. Kline'a göre (2011) çarpıklık (skewness) katsayılarının |3.0|'ten ve basıklık (kurtosis) katsayılarının |10.0|'dan küçük olması normallik göstergesidir. Tablo 1 incelendiğinde çarpıklık (skewness) katsayılarının $|3.0|$ 'ten ve basıklık (kurtosis) katsayılarının $\mid 10.0$ |'dan küçük olduğu görülmektedir. Bu değerlere göre puanların normalliğin sağlandığı kabul edilmektedir. Maddelerin ortalama puanları alındıktan sonra ortalama puanlar üzerinden değişkenler arasında ilişki olup olmadığını görmek için korelasyon katsayılarına bakılmıştır. Analiz sonuçları ve değişkenlere ait betimsel istatistik sonuçları Tablo 1'de sunulmuştur.

\section{Tablo 1.}

Araştırmanın Değişkenlerine İlişkin Betimsel İstatistikler ve Pearson Korelasyon Değerleri

\begin{tabular}{lllcrccc}
\hline Değişkenler & Empati & Yaşam Doyumu & Mutluluk & Ortalama & S.Sapma & Çarpıklık & Basıklık \\
\hline Empati & 1 & & & 54.81 & 6.41 & -1.03 & 1.17 \\
\hline Yaşam Doyumu & $.17^{* *}$ & 1 & & 15.24 & 4.14 & -.14 & -.34 \\
\hline Mutluluk & $.15^{* *}$ & $.51^{* *}$ & 1 & 18.13 & 4.21 & -.60 & .77 \\
\hline Affetme & $.28^{* *}$ & $.19^{* *}$ & $.23^{* *}$ & 30.89 & 6.44 & -.23 & .06 \\
\hline
\end{tabular}

$* * \mathrm{p}<.001$

Tablo 1'de görüldüğü gibi, çarpıklık ve basıklık değerleri açısından empati, yaşam doyumu, mutluluk ve affetme değişkenleri normallik koşullarını sağlamaktadır. Değişkenler arası ilişkinin incelenmesi için yapılan korelasyon sonucunda bütün değişkenler arasında anlamlı bir ilişki bulunmuştur $(\mathrm{p}<.001)$.

Bir sondaki adımda literatür ışığında hipotez model kurulmuştur. Model için toplanan verilerin uygunluğuna dair uyum indeksleri incelenmiştir. Önce ki-kare değerinin serbestlik derecesine oranına, daha sonra TLI ve CFI değerlerine bakılmıştır. TLI ve CFI değerlerinin .95 'ten büyük olması iyi, .90-.94 arasında olması makul düzeyde uyum gösterdiği belirtilmiştir. RMSEA değerinin .05'ten küçük olması iyi, .06-.08 arasında olması ise makul düzeyde uyumun olduğunu göstermektedir (Hu ve Bentler, 1999; Loehlin, 2004). SRMR değerinin ise .10'den küçük olması önerilir ve .05 'ten küçük olması mükemmel uyum gösterdiği belirtilmiştir (Kline, 2005). Modelde empatinin yaşam doyumu ve affetme üzerindeki doğrudan ve mutluluk değişkeni aracıllğıyla etkisi incelenmiştir. Çalıştırılan modelin standardize edilen sonuçları Şekil 2'de, modelin uyum indeksleri ise Tablo 2'de verilmiştir.

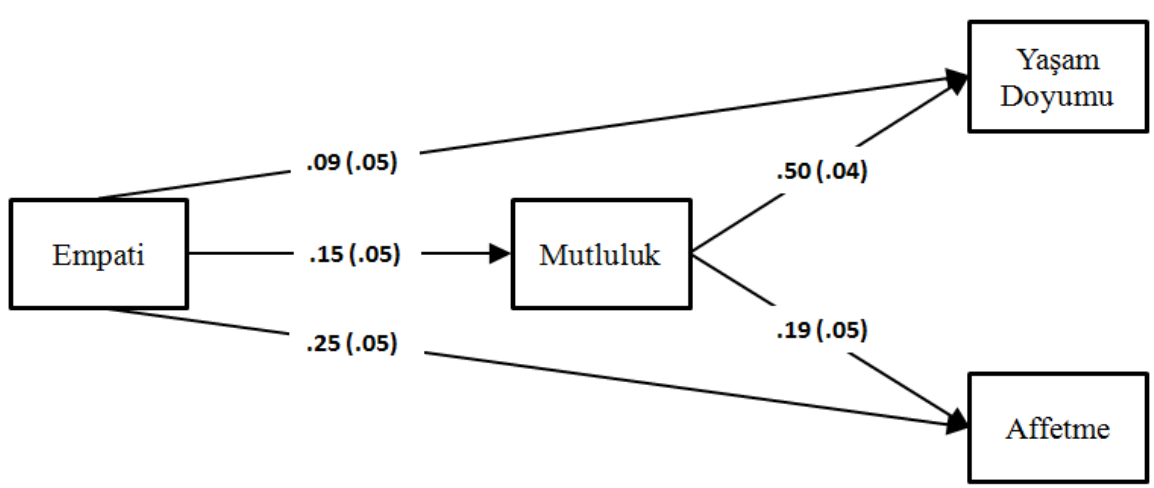

Şekil 2. Standardize Edilmiş Katsayı Değerleri 
Şekil 2'de modelin standardize edilmiş tahmin değerleri verilmiştir. Sonuç olarak empatinin yaşam doyumu ve affetme değişkenleri ile arasındaki ilişkide doğrudan ve dolaylı etkisinin olduğu tespit edilmiştir. Doğrudan etkiler şekil 2'de verildiği gibidir. Bunların yanı sıra etkisi küçük dahi olsa dolaylı etkiler istatistiksel olarak .05 seviyesinde anlamlıdır. Örneğin, empatiden yaşam doyumuna mutluluk değişkeni üzerinden dolaylı etkisi vardır. $\mathrm{Bu}$ etkinin standardize edilmiş değeri .08 'dir.

Tablo 2.

\begin{tabular}{|c|c|c|c|c|c|c|}
\hline$\overline{\chi^{2}}$ & sd & $\chi^{2} / s d$ & CFI & TLI & RMSEA & SRMR \\
\hline 1.582 & 1 & 1.582 & .99 & .978 & .041 & .014 \\
\hline
\end{tabular}

Tablo 2'deki model uyum indeksleri incelendiğinde empati, yaşam doyumu, mutluluk ve affetme değişkenleri arasında kurulan yol modelinin uyum indeksleri verilmiştir. Bu indekslerin belirtilen kritere uygun olduğundan dolayı model-veri uyumunun iyi olduğunu gösterir. Bu bulguların literatüre özgün bir katkı sağlayacağ1 düşünülmektedir.

\section{TARTIŞMA ve SONUÇ}

Araştırmanın sonuçlarına bakıldığında empatinin mutluluk, yaşam doyumu ve affetme değişkenleri ile arasında pozitif yönde anlamlı bir ilişki gösterdiği sonucuna ulaşılmıştır. Bunun yanı sıra mutluluğun yaşam doyumu ve affetme değişkenleri ile arasında pozitif yönde anlamlı bir ilişkiye rastlanmıştır. Psikolojik değişkenler arasındaki ilişsiler aşağıda tartışılmıştır. Empati ve yaşam doyumu arasındaki ilişki pozitif yönde ve manidar düzeydedir. Alan yazın incelendiğinde benzer sonuçların olduğu çalışmalara rastlamak mümkündür (Akkan, 2012).Yavuz (2006) üniversite öğrencileri arasında yapmış olduğu çalışmada yaşam doyumunu yordayan değişkenlerin incelendiği çalışmada empatinin yaşam doyumunu en fazla yordayan değişken olduğu sonucu bulunmuştur. Yetim (2001), kişilerin birbirleri hakkında derin bir anlayış geliştirdikleri ve birbirlerini uyumlu bir biçimde tamamladıkları türden bir sosyal ilişki geliştirdiğinde onların daha mutlu ve yaşam doyumlarının daha yüksek olduğunu vurgulamaktadır. Bireylerdeki empati becerisinin yüksek olduğu düşünüldüğünde yaşamdan aldığı doyumun daha fazla olup daha iyi ilişkilerin geliştirilebileceği düşünülmektedir. Literatür araştırması yapıldığında mutluluk ile yaşam doyumu arasındaki ilişkiyi inceleyen çalışma sayısı yok denecek kadar azdır. Mahon, Yarcheski ve Yarcheski'nin (2005) yapmış olduğu çalışmada kişilerin yaşamlarından aldıkları doyum ne kadar yüksekse mutluluk düzeylerinin de o kadar yüksek olduğu sonucu bulunmuştur sizin kurduğunuz model ile ters orantıl. Sizi mutluysa yaşam doyumu vardır diyorsunuz. Onlar yaşam doyumu varsa mutludur diyor. Sizin kurduğunuz önermenin kuramsal dayanağı ne acaba kafama yatmadı. Siz kurmuş olsaydınız bu kadar soru işareti oluşmayacaktı. . Bal ve Gülcan (2014) üniversite öğrencilerin mutluluk, iyimserlik ve yaşam doyumu düzeyleri arasındaki ilişkiyi incelediği çalışmada mutluluğun yaşam doyumu ile arasındaki ilişkinin pozitif yönde ve manidar düzeyde olduğu sonucuna ulaşılmıştır. Tate (1984) yaptığı çalışmada mutluluğun yaşam doyumunun \%60'ını açıkladığını belirtmiştir. Alan yazında zaman zaman birbirinin yerine kullanılan yaşam doyumu ve mutluluğun arasında bu yönde bir ilişkinin çıkması beklenilen bir sonuçtur. Başka bir deyişle bireylerin yaşamların doyum almaları mutluluk düzeyleri ile ilişkilidir. Empati ile mutluluk arasındaki ilişkinin belirlenmeye çalışıldığı çalışmalara bakıldığında Yavuz (2006) rehberlik ve psikolojik danışmanlık öğrencileri üzerinde yapmış olduğu çalışmada Wei, Liao, Ku ve Schaffer (2011) üniversite öğrencilerinde yaptıkları çalışmada empati ile mutluluk arasında pozitif yönde anlamlı bir ilişkinin olduğunu bulmuştur. Buradan hareketle kişinin başkasını dinleyebildiği ve onu anladığını karşısındakine hissettirmesinin bireye haz verdiğini ve kendini daha mutlu hissettiğini söylemek mümkündür. Empatinin mutluluk ile ilişsisini inceleyen Bourgalt ve diğerlerinin (2015) çalışmasında empatik eğilim arttıkça bireylerin mutlu hissetme düzeylerinin arttığı belirlenmiştir. Söz konusu çalışmada da belirtildiği gibi bireylerin empatik eğilimleri ile kendilerini iyi hissetmeleri arasındaki iliş̧ki göz ardı edilmiş ve daha fazla çalışmaya ihtiyaç olduğu belirtilmiştir. Özellikle topluma hizmet veren psikoloji, psikolojik danışmanlık, sosyal hizmet vb. alanlarda bu çalışmaların yaygınlaşmasının toplum sağlığını ve sunulan hizmetlerin kalitesini arttıracağı düşünülmektedir. Empati ile affetme arasındaki çalışmalar incelendiğinde, iki değişken arasında pozitif yönde anlamlı ilişkinin olduğu çalışmaları görmek mümkündür (Donovan ve Priester, 2017; Macaskill, Maltby ve Day, 2002). Sandage ve Worthington (2010) yaptıkları -deney ve kontrol gruplu- deneysel çalışmada empatinin affetmeyi etkilediğini bulmuşlardır. Bu çalışmada affetme ile ilgilipsikoeğitim programı hazırlanmıştır. $\mathrm{Bu}$ programın her bir oturumunda deney grubuna birer saat olmak üzere toplamda altı saatlik empati semineri verilmiştir. Bu deneysel çalışmanın sonunda deney grubundaki kişilerin affetme puanlarında kontrol grubundaki kişilere göre istatistiksel açıdan anlamlı bir artış olmuştur. Buna dayanarak empatinin affetme üzerinde olumlu yönde bir etkisi olduğunu söylemek mümkündür. Younger, Piferi, Jobe ve Lawler (2004) empatinin affetmeye aracılık ettiğgini ve fedakârca bir davranış olduğunu belirtmişlerdir. Kişi suçlunun davranışlarını onun bakış açısıyla anlamak ve onun hissettiklerini hissetmek için empati kurmalıdır. Worthington, Kurusu, Collins ve Berry (2000) yapmış oldukları çalışmada empatinin affetmeyi arttırdığı sonucuna ulaşııııştır. Araştırma sonuçlarına paralel olarak bu çalışmalar ışığında empatinin affetme ile ilişkili olduğu ve affetme düzeyini etkilediği sonucu çıkarılabilir. Bu araştırmada mutluluk ve affetme arasındaki ilişkinin pozitif yönde ve anlamlı olduğu sonucuna 
ulaşılmıştır. Literatüre bakıldığında benzer sonuçlara rastlamak mümkündür (Lawler-Row ve Piferi, 2006; Maltby, Day ve Barber, 2005). Karremans, Van Lange, Ouwerkerk ve Kluwer (2003) yaptıkları çalışmada mutluluk ile affetme kavramının ilişsisine dikkat çekmiştir. Affeden kişilerin daha mutlu olduğu sonucuna ulaşılmıştır. Bu ilişki tersi şeklinde de düşünülebilir. Mutlu insanların daha affedici eğilimler gösterebileceği düşünülebilir mutluluk çok kapsamlı ve durumsal değişkenlikler gösterebiliyor o yüzden mutlu insanlar affedici eğilimler gösterir demek ne kadar doğru? Chan (2013) yaptığı çalışmada mutluluğun affetme ile ilişkili olduğunu ve affetmenin önemli bir yordayıcısı olduğunu ifade etmiştir. Çalışmasında mutluluğun affedici bir kişi olmada etkili olduğunu savunan Chan, affeden bireylerin de kendilerini daha mutlu hissettiğini belirtmiştir. Dolayısıyla mutluluk ve affetmenin birbirini iki yönlü etkileyen kavramlar olduğu düşünülebilir.

Hipotez modelde mutluluğun empati ile yaşam doyumu ve affetme arasında aracı rolünün olduğu varsayılmıştır. Oluşturulan modelin sonuçlarına bakıldığında empatinin affetme ve yaşam doyumu arasında hem doğrudan hem de mutluluk aracılığg ile dolaylı olarak ilişkisinin olduğu bulunmuştur. Mutluluğun empati ile yaşam doyumu arasındaki ilişkide modele aracı olarak sokulmasının hata oranını değiştirmezken tahmin katsayısını arttırdığını göstermektedir. $\mathrm{Bu}$ da beklenen bir durumdur. Empatinin yaşam doyumuyla arasındaki ilişki literatürdeki çalışmalarla desteklenmiştir. Fakat üniversite öğrencilerinin empati düzeylerinin mutluluk aracılığı ile yaşam doyumlarında artış sağladığını gösteren bir çalışmaya rastlanmamıştır. Mutluluğun aracılığı empati ile yaşam doyumu arasındaki ilişkiyi güçlendirmiş ve empatinin yaşam doyumunu tahmin edebilirliğini arttırmıştır. Aynı şekilde empatinin affetme ile arasındaki anlamlı ilişkide mutluluk değişkeni üzerinden dolaylı etkisindeki hata oranı değişmezken tahmin katsayısında düşme görülmüştür. Tahmin katsayısının düşmesi modelin çalışmasını engellememesiyle birlikte, aracı değişkenin (mutluluğun) varlığı tahmin katsayısını etkilediği yorumu yapılabilir. $\mathrm{Bu}$ durum empati ile affetme arasındaki ilişkiyi kuvvetlendiren mutluluk dışında farklı değişkenlerin olabileceği şeklinde açıklanabilir.

$\mathrm{Bu}$ araştırmada bazı sınırlılıklar vardır. Bu sınırlılıklardan birisi, elde edilen verilerin üniversitede öğrenim gören öğrencilerinden elde edilmiş olmasıdır. Diğer bir sınırlılık araştırmada oluşturulan modelde yalnızca empati, mutluluk, yaşam doyumu ve affetme değişkenlerine yer verilmiş olmasıdır. Bu çalışmada path analizi kullanılmıştır. Çalışmadaki örneklem sayısı arttırılarak yapısal eşitlik modellemesi yapılabilir ve daha iyi sonuçlar veren bir model oluşturulabilirdi. Bu çalışmanın sınırlı bir yanı olabilir.

Araştırmanın sonuçları ve sınırlılıkları doğrultusunda şu öneriler getirilebilir. Değişkenler literatürdeki diğer çalışmalarda olduğu gibi bir psikoeğitim programı hazırlanarak bireylerdeki gelişim izlenebilir. Çalışılan kavramlar birbiri ile yakından ilişkili ve iç içe kavramlardır. Bu sebeple söz konusu kavramlarla ilişkili farklı desenlerin (nitel, deneysel vb.) kurulacağı çalışmalar gerçekleştirilebilir. Bununla birlikte psikoloji ve psikolojik danışmanlık ve rehberlik alanındaki üniversite öğrencilerine, bu kavramların terminolojisini daha iyi aktarabilmek için bu kavramlara ders kitaplarında daha fazla yer verilebilir. Psikolojik iyi oluş, yaşam doyumu, mental iyi oluş, mutluluk ve öznel iyi oluş kavramları ile ilgili çalışmaların sayısı arttırılarak aralarındaki farklılıkların belirlenmesi sağlanabilir. Araştırmada kurulan hipotez model beklenen değerlerle paralellik göstermektedir. Aynı değişkenler literatür ışığında farklı modellerle sınanarak çıkan değerler kıyaslanabilir. Bu farklılığın sonucunda literatüre katkı sağlanabilir. 


\section{KAYNAKÇA}

Akarsu, B. (1997). Mutluluk ahlakı. İstanbul: İnkılap Yayınevi.

Akın, A. ve Satıcı, S. A. (2011). Öznel mutluluk ölçeği: Geçerlik ve güvenirlik çalışması. Sakarya Üniversitesi Eğitim Fakültesi Dergisi, 21, 65-77.

Akkan, H. (2012). Üstün zekâlı 6-8. sınıföğrencilerinin iki farklı akademik ortamdaki sosyometrik statülerine göre empatik eğilimleri, yaşam doyumları ve aile yaşantıları. Yüksek lisans tezi. Dokuz Eylül Üniversitesi, Eğitim Bilimleri Enstitüsü, İzmir.

Alpay, A. (2009). Yakın ilişkilerde bağışlama: Bă̆ışlamanın; bağlanma, benlik saygısı, empati ve kıskançlık değişkenleri yönü̈nden incelenmesi. Yüksek lisans tezi. Ankara Üniversitesi, Sosyal Bilimler Enstitüsü, Ankara.

Anderson, K., and Costello, P. (2009). Relationships between prosocial behavior, spirituality, narcissism, and satisfaction with life. Journal of Gustavus Undergraduate Pshychology, 5, 1-28.

Asıcı, E. (2013). Öğretmen adaylarının affetme özelliklerinin öz-duyarlık ve benlik saygısı açısından incelenmesi. Yüksek lisans tezi. Dokuz Eylül Üniversitesi, Eğitim Bilimleri Enstitüsü, İzmir.

Bal, P. N. ve Gülcan, A. (2014). Genç yetişkinlerde iyimserliğin mutluluk ve yaşam doyumu üzerindeki etkisinin incelenmesi. E-AJI (Asian Journal of Instruction), 2(1(Özel)), 41-52.

Barrington-Leigh, C. P., and Helliwell, J. F. (2008). Empathy and emulation: Life satisfaction and the urban geography of comparison groups (No. w14593). National Bureau of Economic Research.

Baştuğ, G. (2009). Voleybol antrenör adaylarının empatik becerileri ile yaşam doyumları arasındaki ilişkinin incelenmesi. Niğde Üniversitesi Beden Eğitimi ve Spor Bilimleri Dergisi, 3(3), 222-227.

Bélanger, C., Laporte, L., Sabourin, S., and Wright, J. (2015). The effect of cognitive-behavioral group marital therapy on marital happiness and problem solving self-appraisal. The American Journal of Family Therapy, 43(2), 103-118.

Berry, J. W., Worthington, E. L., O’Connor, L. E., Parrott, L., and Wade, N. G. (2005). Forgivingness, vengeful, rumination, and affective traits. Journal of Personality, 73, 1-43.

Bourgault, P., Lavoie, S., Paul-Savoie, E., Grégoire, M., Michaud, C., Gosselin, E., and Johnston, C. C. (2015). Relationship between empathy and well-being among emergency nurses. Journal of Emergency Nursing, 41(4), 323-328.

Bozoğlan, B. (2014). Çatışmanın yordayıcısı olarak sosyal destek ve yaşam doyumu. Kastamonu Eğitim Dergisi, 22(1), 161-175.

Chan, D. W. (2013). Subjective well-being of Hong Kong Chinese teachers: The contribution of gratitude, forgiveness, and the orientations to happiness. Teaching and Teacher Education, 32, 22-30

Cohn, M. A., Fredrickson, B. L., Brown, S. L., Mikels, J. A., and Conway, A. M. (2009). Happiness unpacked: Positive emotions increase life satisfaction by building resilience. Emotion, 9(3), 361-368.

Çankaya, Z. C. (2008). Bazı insanlar neden daha mutludur? Öznel iyi olma sürecinde psikolojik ihtiyaçların rolü. Aile ve Toplum Eğitim- Kültür ve Araştırma Dergisi, 13(1), 2: 29-36.

Çardak, M. (2012). Affedicilik yönelimli psiko-eğitim programının affetme eğilimi, belirsizliğe tahammülsüzlük, psikolojik iyi oluş, sürekli kaygl ve öfke üzerindeki etkisinin incelenmesi. Doktora tezi. Sakarya Üniversitesi, Eğitim Bilimleri Enstitüsü, Sakarya.

Çevik, N. (2010). Lise öğrencilerinin öznel iyi oluşlarını yordayan bazı değişkenler. Yüksek lisans tezi, Gazi Üniversitesi, Eğitim Bilimleri Enstitüsü, Ankara.

Demiralp, C. (2017). Üniversite öğrencilerinin empatik eğilim ile narsistik kişilik özellikleri ve eleştirel düşünme arasindaki ilişkinin incelenmesi. Yüksek lisans tezi, Atatürk Üniversitesi, Eğitim Bilimleri Enstitüsü, Erzurum.

Demirel S., Acar Ö., Karakurt E., Onaygil C. ve ark., Yurt yaşamının üniversite öğrencilerinin sağlığı üzerindeki etkileri, MASCO, Marmara Öğrenci Kongresi, 16-17 Mayıs, 2006

Demirel, S., ve Canat, S. (2004). Ankara'daki beş eğitim kurumunda kendini yaralama davranışı üzerine bir çalışma. Kriz Dergisi, 12(3), 1-9 
Derman, M. (2011). Farklı sosyoekonomik düzeylerdeki 10-11 yaş çocuklarına uygulanan empati eğitim programının saldırganlık düzeyleri üzerindeki etkisi. Doktora tezi. Uludağ Üniversitesi, Eğitim Bilimleri Enstitüsü, Bursa.

Diener, E. (1984). Subjective well-being. Psychological Bulletin, 95, 542-575.

Diener, E., Emmons, R. A., Larsen, R. J. and Griffin, S. (1985), The Satisfaction with Life Scale. Journal of Personality Assessment, 49(1), 71-75.

Diener, E., Suh, E. M., Lucas, R. E., and Smith, H. L. (1999). Subjective Well Being: Three Decades of Progress. Psychological Bulletin, 125(2), 276- 302.

Dillon, R. S. (2001). Self-forgiveness and self-respect. Ethics, 112(1), 53-83.

Donovan, L. A. N., and Priester, J. R. (2017). Exploring the psychological processes underlying interpersonal forgiveness: The superiority of motivated reasoning over empathy. Journal of Experimental Social Psychology, 71, 16-30.

Dökmen, Ü. (2004). Empati. İstanbul: Remzi Kitabevi.

Eaton, J., Struthers, C. W., and Santelli, A. G. (2006). Dispositional and state forgiveness: The role of self-esteem, need for structure, and narcissism. Personality and Individual Differences, 41(2), 371-380.

Enright, R. D., and The Human Development Study Group (1996). Counseling within the forgiveness triad: On forgiving, receiving forgiveness, and self-forgiveness. Counseling and Values, 40, 107-126.

Erkutlu, H. (2014). Exploring the moderating effect of psychological capital on the relationship between narcissism and psychological wellbeing. Social and Behavioral Sciences, 150(2014), 1148-1156.

Eryılmaz, A. ve Öğülmüş, S. (2010). Ergenlikte öznel iyi oluş ve beş faktörlü kişilik modeli. Ahi Evran Üniversitesi Eğitim Fakültesi Dergisi, 11(3), 189-203.

Exline, J. J., Worthington, E. L., Hill, P., and McCullough, M. E. (2003). Forgiveness and justice: A research agenda for social and personality psychology. Personality and Social Psychology Review, 7(4), 337 348.

Fincham, F. D., Beach, S. R., and Davila, J. (2004). Forgiveness and conflict resolution in marriage. Journal of Family Psychology, 18(1), 72.

Fincham, F. D., Hall, J. H., and Beach, S. R. H. (2006). Forgiveness in marriage: Current status and future directions. Family Relations, 55, 425-427.

Hacı, Y. (2011). Evlilik uyumunun empatik eğilim, algllanan aile içi iletişim ve çatışma çözme stillerine göre yordanması. Yüksek lisans tezi. Ege Üniversitesi, sosyal Bilimler Enstitüsü, İzmir.

Hall, J. H., and Fincham, F. D. (2005). Self-forgiveness: The stepchild of forgiveness research. Journal of Social and Clinical Psychology, 24, 621-637.

Hoffmann, M. (1978). "Empathy, Its Development and Prosocial Implacations”. Bulunduğu eser: C.B: Keasey (ed.), Nebraska Symposium on Motivation, 25: 169:128.

Hofmann, W., Luhmann, M., Fisher, R. R., Vohs, K. D., and Baumeister, R. F. (2014). Yes, but are they happy? Effects of trait self-control on affective well-being and life satisfaction. Journal of Personality, 82(4), 265-277.

Kangal, A. (2013). Mutluluk üzerine kavramsal bir değerlendirme ve Türk hanehalkı için bazı sonuçlar. Elektronik Sosyal Bilimler Dergisi, 12(44), 214-233.

Karataş, Z. (2012). Eğitim fakültesi öğrencilerinin empatik becerileri ve benlik saygısı düzeylerinin incelenmesi, Mehmet Akif Ersoy Üniversitesi Ĕ̈itim Fakültesi Dergisi, 12 (23), 97-114.

Karremans, J. C., Van Lange, P. A., Ouwerkerk, J. W., and Kluwer, E. S. (2003). When forgiving enhances psychological well-being: the role of interpersonal commitment. Journal of Personality and Social Psychology, 84(5), 1011.

Kaya, Ö. S. (2018). Romantik ilişkilerde problem çözme becerilerinin empati ve mental iyi oluş açısından incelenmesi. Yüksekögretim ve Bilim Dergisi, 8(1), 1-11.

Kaya, Ö. S., ve Demir, E. (2017). Kendini toparlama gücü ve stresle başa çıkma stratejilerinin mutluluk düzeyini yordama gücü. Sakarya Üniversitesi Eğitim Fakültesi Dergisi, 33, 18-33. 
Keser, A. (2003). Çalışmanın anlamı, insan yaşamındaki yeri ve yaşam doyumu üzerine bir uygulama. Yayımlanmamış doktora tezi. Uludağ Üniversitesi, Sosyal Bilimler Enstitüsü, Bursa.

Kiraz, C. (2011). Eğitim fakültesi ögrencilerinin empatik eğilimleri ile narsistik kişilik özellikleri. Yüksek lisans tezi. Yeditepe Üniversitesi, Sosyal Bilimler Enstitüsü, İstanbul.

Kline, R. B. (2011). Convergence of structural equation modeling and multilevel modeling. na.

Koç, M., İskender, M., Çolak, T. S., and Düşünceli, B. (2016). Investigation of the effect of intolerance of uncertainty and the effect of anger control on the relationship between forgiveness and psychological well-being through structural equation modelling. Sakarya University Journal of Education, 6(3), 201209.

Köroğlu, M. (2012). Emniyet personelinin empatik ĕgilim becerileri, çatışma ve şiddete ilişkin farkındalıkları ile çatışma çözme stilleri. Doktora tezi. Necmettin Erbakan Üniversitesi, Eğitim Bilimleri Enstitüsü, Konya.

Lawler-Row, K. A. and Piferi, R. L. (2006). The forgiving personality: Describing a life well lived?. Personality and Individual Differences, 41(6), 1009-1020.

Lawler-Row, K. A., Younger, J. W., Piferi, R. L., and Jones, W. H. (2006). The role of adult attachment style in forgiveness following an interpersonal offense. Journal of Counseling and Development, 84(4), 493502 .

Lee, H. S., Brennan, P. F., and Daly, B. J. (2001). Relationship of empathy to appraisal, depression, life satisfaction, and physical health in informal caregivers of older adults. Research in Nursing \& Health, 24(1), 44-56.

Lyubomirsky, S. (2001). Why are some people happier than others? The role of cognitive and motivational processes in well-being. American Psychologist, 56, 239-249.

Lyubomirsky, S., King, L., and Diener, E. (2005). The benefits of frequent positive affect: Does happiness lead to success? Psychological Bulletin, 131, 803-855.

Lyubomirsky, S., Tkach, C., and DiMatteo, M. R. (2006). What are the differences between happiness and selfesteem. Social Indicators Research, 78(3), 363-404.

Macaskill, A., Maltby, J., and Day, L. (2002). Forgiveness of self and others and emotional empathy. Journal of Social Psychology 142, 663-665.

Mahon, N. E., Yarcheski, A., and Yarcheski, T. J. (2005). Happiness as related to gender and health in early adolescents. ClinicalNnursing Research, 14(2), 175-190.

Maltby, J., Day, L., and Barber, L. (2005). Forgiveness and happiness, the differing contexts of forgiveness using the distinction between hedonic and eudaimonic happiness. Journal of Happiness Studies, 6, 1-13.

Maltby, J., Macaskill, A., and Day, L. (2001). Failure to forgive self and others: A replication and extension of the relationship between forgiveness, personality, social desirability and general health. Personality and Individual Differences, 30(5), 881-885.

Neugarten, B. L., Havighurst, R. J., and Tobin, S. S. (1961). The Measurement of Life Satisfaction. Journal of Gerentology, 16, 134-143.

Özbek, M. (2004). Toplumsal yaşamda empati. Uluslararası Hakemli Sosyal Bilimler E-Dergisi, 1, 1-16.

Özdemir, N., ve Koruklu, Y. (2011). Üniversite öğrencilerinde değerler ve mutluluk arasındaki ilişkinin incelenmesi. Yüzüncü Yıl Üniversitesi Eğitim Fakültesi Dergisi, 8(1), 190-210.

Özdevecioğlu, M. (2003). İş tatmini ve yaşam tatmini arasındaki ilişkinin belirlenmesine yönelik bir araştırma. 11.Ulusal Yönetim ve Organizasyon Kongresi, Afyon.

Peterson, C., Park, N., and Seligman, M. E. (2005). Orientations to happiness and life satisfaction: The full life versus the empty life. Journal of Happiness Studies, 6(1), 25- 41.

Peterson, C., Ruch, W., Beermann, U., Park, N., and Seligman, M. E. (2007). Strengths of character, orientations to happiness, and life satisfaction. The Journal of Positive Psychology, 2(3), 149-156

Rangganadhan, A. R., and Todorov, N. (2010). Personality and self-forgiveness: The roles of shame, guilt, empathy and conciliatory behavior. Journal of Social and Clinical Psychology, 29(1), 1-22. 
Russel, B. (2003). Mutluluk Yolu, (Çev.: N. Özyürek), Varlık Yayınları: İstanbul.

Salı, G. (2013). İlköğretim ikinci kademedeki çocukların empatik eğilimlerinin ve benlik kavramlarının incelenmesi. Kuramsal Eğitimbilim Dergisi, 6(4), 496-519.

Sandage, S. and Worthington Jr, E. (2010). Comparison of two group interventions to promote forgiveness: Empathy as a mediator of change. Journal of Mental Health Counseling, 32(1), 35-57.

Sarıçam, H. ve Akın, A. (2013). Affedicilik ölçeğinin türkçe uyarlaması: Geçerlik ve güvenirlik çalışması. Hasan Ali Yücel Eğitim Fakültesi Dergisi, 19, 37-46.

Schafer, J. L. (1997). Analysis of incomplete multivariate data. CRC press

Seligman, M. E. P. (2002). Gerçek Mutluluk. Çev: Semra Kunt Akbas. Ankara: HYB Basım Yayın.

Shanafelt, T. D., West, C., Zhao, X., Novotny, P., Kolars, J., Habermann, T., and Sloan, J. (2005). Relationship between increased personal well-being and enhanced empathy among. Journal of General Internal Medicine, 20(7), 559-564.

Snow, N. E. (1993). Self forgiveness. The Journal of Value Inquiry, 27, 75-80.

Spreng, R. N., Kinnon, C. M., Mar, R. A., and Levine, B. (2009). The Toronto Empathy Questionnaire: Scale development and initial validation of a factor-analytic solution to multiple empathy measures. Journal of Personality Assessment, 91(1), 62-71.

Strelan, P. (2007). Who forgives others, themselves, and situations? The roles of narcissism, guilt, self-esteem, and agreeableness. Personality and Individual Differences, 42(2), 259-269.

Tarhan, N. (2005). Mutluluk Psikolojisi, Timaş Yayınları: İstanbul.

Tate, U. S. (1984). Convergent and discriminant validity of measures of job, leisure, dyadic, and general life satisfaction by causal modeling methodology. Journal of Leisure Research, 16(3), 250-254.

Thomas, M. R., Dyrbye, L. N., Huntington, J. L., Lawson, K. L., Novotny, P. J., et al. (2007). How do distress and well-being relate to medical student empathy? A multicenter study. Journal of General Internal Medicine, 22(2), 177-183.

Thompson, L.Y., Snyder, C.R., Hoffman, L., Michael, S.T., Rasmussen, H.N., et al. (2005). Dispositional forgiveness of self, others, and situations. Journal of Personality, 73, 313-359.

Totan, T., Dogan, T., ve Sapmaz, F. (2012). The Toronto Empathy Questionnaire: Evaluation of psychometric properties among turkish tniversity students. Eurasian Journal of Educational Research, 46, 179-198.

Toussaint, L. and Webb, J. R. (2005). Gender differences in the relationship between empathy and forgiveness. The Journal of Social Psychology, 145(6), 673-685

Twenge, M. J., and Campbell K. W. (2010). Asrın vebası narsisizm illeti (çev. Korkmaz Ö). İstanbul: Kaknüs Yayınları.

Veenhoven, R. (1996). The Study of Life Satiscaftion, A Comparative Study of Satisfaction With Life in Europe. (Saris W. E., Veenhoven, R., Scherpenzeel, A. C. and Bunting, B., Eds), Budapest, Hungary: Eötvös University Pres, 11-48.

Walker, D. F. and Gorsuch, R. L. (2004). Dimensions underlying sixteen models of forgiveness. Journal of Psychology and Theology, 32, 12-25.

Wei, M., Liao, K. Y. H., Ku, T. Y., and Shaffer, P. A. (2011). Attachment, self-compassion, empathy, and subjective well-being among college students and community adults. Journal of Personality, 79(1), 191-221.

Worthington Jr, E. L. (1998). Empirical research in forgiveness: Looking backward, looking forward. Dimensions of forgiveness: psychological research and theological perspectives. E.L. Worthington Jr (Ed.). Philadelphia: Templeton Foundation Press, pp. 321-339.Wilson, W. R. (1967). Correlates of avowed happiness. Psychological Bulletin, 67(4), 294-306.

Winnet, A. (2001). Empathy in communication, self improvement online. http://www.selfgrowth.com adresinden erişilmiş̧tir. 
Worthington Jr, E. L., Kurusu, T. A., Collins, W., and Berry, J. W. (2000). Forgiving usually takes time: A lesson learned by studying interventions to promote forgiveness. Journal of Psychology and Theology, 28(1), 3-20.

Worthington, E. L. (2006). Forgiveness and reconciliation: Theory and Application. New York: Routledge Press.

Yavuz, Ç. (2006) Rehberlik ve psikolojik danışmanlık öğrencilerinde öznel iyi olma, psikiyatrik beliktiler ve bazı kişilik özellikleri: Karşılaştırmalı bir çalışma. Yüksek lisans Tezi. İstanbul Üniversitesi, Eğitim Bilimleri Enstitüsü, İstanbul.

Yetim, Ü. (1991). Kişisel projelerin organizasyonu ve örüntüsü açısından yaşam doyumu. Doktora Tezi. Ege Üniversitesi, Sosyal Bilimler Enstitüsü, İzmir.

Yetim, Ü. (2001). Toplumdan Bireye Mutluluk Resimleri. İstanbul: Bağlam Yayınları.

Yıldız, M. A., ve Baytemir, K. (2016). Evli bireylerde evlilik doyumu ile yaşam doyumu arasındaki ilişkide benlik saygısının aracılığı. İnönü Üniversitesi Eğitim Fakültesi Dergisi, 17(1), 67-80.

Yılmaz, N. (2011). Okul öncesi öğretmenlerinin iletişim becerileri, problem çözme becerileri ve empatik ĕgilim düzeyleri. Yüksek lisans tezi. Muğla Üniversitesi, Eğitim Bilimleri Enstitüsü, Muğla.

Younger, J. W., Piferi, R. L., Jobe, R. L., and Lawler, K.A. (2004). Dimensions of forgiveness: The views of laypersons. Journal of Social and Personal Relationships, 21(6), 837-855.

Ysseldyk, R., and Matheson, K. (2008). Forgiveness and coping. Women's Reflections on the Complexities of Forgiveness, 143-163.

Yüksel, A. (2004). Empati eğitim programının ilköğretim öğrencilerinin empatik becerilerine etkisi. Uludağ Üniversitesi Ĕ̈itim Fakültesi Dergisi, 17(2), 341-354. 


\section{EXTENDED ABSTRACT}

\section{Introduction}

Human beings seek for nutrition, protection and healthy and safe environment to continue their lives. During their lives, they experience so many things. These experiences help them to develop their personality and create their social environments. As social creatures, human beings interact with each other during their all life times. They communicate with each other anytime such as during their academic or work life, while they are shopping or traveling at a public transportation. It is very important for people who interact with each other to reach a health understanding and a good result in order to fulfill the expectations from each other. Putting yourself for someone else place and taking their feelings and thoughts into account is defined as empathy. Empathy is a process which improves and reinforces the relations between people and makes easier to understand each other. Empathize with someone else causes for the person to feel better and important. Moreover, a person who things that his or her emotions and thoughts are understood feels reassured and given importance. That is to say, a person who thinks that he or she is understood by others feels being important and happy. Therefore, he or she shares their ideas more freely.

Considering the effect of empathy for the role of fixing human relationship, its direct effect on people's mood cannot be neglected. It is obvious that each individual's goal is to live a happy and peaceful life. People struggle hard for that. Despite the struggle, trouble and misery are unavoidable. For people to be happy or not is up to life they maintain and level of life satisfaction. People upset or offend each other because of the problems that face at their relationships. However, they may also aim to forgive each other after a certain experience. It is believed that when people are happy they become more forgiven and enjoy their life more. Considering all above, it might be correct to conclude that being able to empathize with others causes people to be more happy, satisfy their life and forgiven others more. Therefore, the aim of this study is to explore whether happiness is mediator among empathy, life satisfaction and forgiveness for college students (as shown in figure 2).

\section{Method}

The data were collected from a university at north east of Turkey during the 2016 - 2017 school year. The sample was selected randomly with the size of 351. 209 them were female students. The average age of the sample was 20.3. The minimum and maximum ages were 18 and 24 respectively. For the data collection personal information form and Turkish version of Toronto Empathy Scale (Totan, Doğan and Sapmaz, 2012), Life Satisfaction Scale (Yetim, 1991), Subjective Happiness Scale (Akın and Satıcı, 2011) and Forgiveness Scale (Sarıçam and Akın, 2013) were used in this study. The data were first analyzed with SPSS to calculate Pearson correlation. Later, in order to answer the main research question, Mplus 5.1 program was utilized to test hypothesized path model which is shown in figure 2 .

\section{Findings, Discussion and Results}

First of all, the cases with missing were cleared from the data set. Then, Cronbach Alpha was calculated for each scale score. Later, distributions of the scale scores were examined. All the skewness and kurtosis values were between -2 and +2 ; therefore, considered as normally distributed.

The relationships among the variables were explored via Pearson correlation. Based on the results, there existed positive correlation between empathy and happiness $(\mathrm{r}=.15, \mathrm{p}<.001)$, between empathy and life satisfaction $(\mathrm{r}=$ $.17, \mathrm{p}<.001)$ and between empathy and forgiveness $(\mathrm{r}=.28, \mathrm{p}<.001)$. Moreover, there also existed positive correlation between happiness and life satisfaction $(\mathrm{r}=.51, \mathrm{p}<.001)$, between happiness and forgiveness $(\mathrm{r}=.23$, $\mathrm{p}<.001)$ and between forgiveness and life satisfaction $(\mathrm{r}=.19, \mathrm{p}<.001)$.

A hypnotized model was introduced for the current study (see figure 2). The model was tested by using Mplus 5.1. Since the data were normally distributed Maximum Likelihood estimation method was used for the analysis. Model data fits were examined with Chi square, CFI, TLI, RMSEA and SRMR values. Standardized values of the model parameters were reported. Based on the result, model data fit $\operatorname{was} \operatorname{good}\left(x^{2}=1.582, s d=1, C F I=.996, T L I=.978\right.$, $R M S E A=.041, S R M R=.014)$. The standardized parameter estimates were reported at figure 2. For example, there was a significant direct effect from empathy to forgiveness and its parameter estimate was $.25(.05)$. Besides, there exists an indirect effect from empathy to forgiveness. Thus, empathy has direct and indirect effects on life satisfaction and forgiveness. That is to say that happiness is a mediator variable in the relationship among empathy, life satisfaction and forgiveness.

The literature was explored to see the studies focused on the relationship between endplay and life satisfaction. Results of the current study were comparable with the literature. Baştuğ (2009) has studied physical education 
teacher candidates and found that there was a positive significant correlation between the variables. Besides, Yavuz (2006) worked on university students. He found that among others empathy was the strongest predictors for life satisfaction. Additionally, Toussaint and Webb (2005) have found that there was a significant correlation between empathy and forgiveness. Besides the direct effect indicated in the literature, this study also showed happiness was a mediator variable. The literature showed that happiness has direct effects on empathy, life satisfaction and forgiveness (Yavuz, 2006; Çardak, 2012; Bal and Gülcan, 2014). However, there was no study showing happiness as a mediator between the dependent and independent variables. Therefore, this study added this information to the literature and leads new research areas for the variables. 